\title{
Silêncio dentro da sala de aula
}

Resumo: Este artigo tem como propósito apresentar os resultados de um estudo sobre as seguintes questões: como se constitui o silêncio dentro do ambiente escolar e em que momentos ele atrapalha ou ajuda nas aprendizagens dos sujeitos no processo educativo. A pesquisa é de cunho qualitativo e foi desenvolvida em uma escola de ensino fundamental da rede municipal de Osório, cidade do litoral norte do Rio Grande do Sul. A coleta de dados foi realizada através de entrevistas a professores e a alunos das séries iniciais e observações em sala de aula para verificar as concepções que esses sujeitos têm a respeito do silêncio como articulador na construção de conhecimentos dentro do ambiente escolar.

Palavras-chave: Pedagogia do silêncio. Aprendizagem. Ambiente escolar.

\section{Introdução}

O silêncio imposto pela escola, pelo professor é algo que, muitas vezes, pode deformar e podar a personalidade do indivíduo que está se formando. Como ato disciplinador, é um dos instrumentos que o professor tem ao seu alcance para obter o controle sobre os alunos, fazendo com que a sala de aula tenha ordem e que somente o mestre tenha a palavra e o aprendiz a escute.

Hoje está em evidência falar em aluno crítico, participativo, interessado pelo que está aprendendo. Ele deve interagir nas aulas e expressar ideias para que possa construir e produzir conhecimentos em conjunto com colegas e professor. Mas, o que ainda é visto, é um ato regulador, ou seja, se o aluno tiver liberdade de expressão, a aula corre o risco de se tornar uma bagunça. Para que se possa atingir o objetivo de formar cidadãos que tenham o entendimento e a força da palavra, é necessário que a sala de aula deixe de ser silenciosa e torne-se um ambiente propício para interações e para troca de saberes entre os sujeitos participantes.

Com esse intuito, a pesquisa em questão aborda esse tema através de entrevistas e observações que foram desenvolvidas em escolas públicas e particulares situadas no município de Osório, litoral norte do Estado do Rio Grande do Sul, localizado a 100 quilômetros da capital gaúcha- Porto Alegre. O objetivo é identificar como o silêncio é proposto dentro da sala de aula e como é a construção dos saberes dos aprendizes em questão.
Christiane Jaroski Barbosa

Professora da Faculdade Cenecista de Osório-RS

christianejb@gmail.com

Mari Teresinha Panni de Borba Faculdade Cenecista de Osório-RS maripanni@gmail.com 


\section{Algumas concepções são assim}

Silêncio dentro da sala de aula pode representar construção de conhecimento? Ou é uma das formas que o professor tem de ter domínio sobre sua turma? Quando é pensado o ambiente escolar, logo se remete à ideia de concentração, ouvidos atentos ao que o professor está falando e muito silêncio para entender o que está sendo proposto.

Sabe-se que, através das práticas e estudos de autores, o saber não se constitui do silêncio, mas nas trocas, no diálogo, nos debates, desenvolvendo assim o senso crítico dos participantes em questão.

A criança que pouco fala, não incomoda, não prejudica o desempenho planejado pelo professor. Ele tem um objetivo e, no momento que houver conversa e interação, o seu objetivo pode se desvirtuar. Foucault (2004, p. 118) fala "[...] do homem máquina, corpo útil é corpo inteligível, ou seja, o sujeito só é considerado inteligente se, de alguma forma, ele servir aos propósitos do poder". Ele denomina isso de corpos dóceis, corpos esses que são treinados para obedecer, se subjugar sem ter a possibilidade de pensar ou fazer o que lhe convém. As palavras do mesmo autor retratam bem como é pensado e qual o fundamento em formar corpos dóceis.

É preciso anular os efeitos das repartições indecisas, o desaparecimento descontrolado dos indivíduos, sua circulação difusa, sua coagulação inutilizável e perigosa; tática de antideserção, de antivadiagem, de antiaglomeração. Importa estabelecer as presenças e ausências, saber onde e quando encontrar os indivíduos, instaurar as comunicações úteis, interromper as outras, poder a cada instante vigiar o comportamento de cada um, apreciá-lo, sancioná-lo, medir as qualidades e os méritos. Procedimento, portanto, para conhecer, dominar e utilizar. (FOUCAULT, 2004, p. 118)

Em concordância com Foucault (2004), as regras impostas no espaço escolar já vêm de muitos anos atrás e ainda prevalecem, mesmo sendo normas arcaicas e desatualizadas diante do atual momento. Estas regras estabelecem formas de constituir, de formar sujeitos, com o propósito de moldá-los de acordo com os interesses dos mecanismos de poder vigentes. Todas as regras que existem dentro da escola seguem a determinação de que a criança não pode ter liberdade, pois, como está em formação, deve seguir obedecendo ao que lhe é imposto. 
A escola tem o papel de formar para o futuro, para a constituição de um adulto que possa estar apto para conquistar um bom emprego e ter sucesso no que faz. Para isso acontecer, o tempo de frequência na escola, principalmente o da criança, deve ser de disciplina e rigor. Regras devem ser obedecidas, porém muitas estão longe de proporcionar espaços de interação e diálogo entre os alunos. Freire (2006, p. 66) defende o ideal de educação voltada para as trocas, aceitação do novo e principalmente o diálogo entre mestre e aprendiz. "O respeito à autonomia e à dignidade de cada um é um imperativo ético e não um favor que podemos ou não conceder uns aos outros". A comunicação não só é algo que faz parte da natureza do ser humano, como também é necessária para situar-se no ambiente, na sociedade em que se vive.

Gimeno Sacristan (2002, p. 41) também defende a concepção de sujeito comunicativo, de interação e de movimento, para ele, isso faz parte da aprendizagem.

O ser humano é um ser social - por isso também é um ser cultural - e, através do exercício dessa condição, aproveita a cultura comunicada entre os indivíduos. A experiência individual é, essencialmente, mediada e nutrida pela dos semelhantes com os quais estabelecemos comunicação no âmbito das redes sociais das quais participamos.

Há um ponto muito discutido relacionando silêncio e disciplina. Muitos professores falam da liberdade dentro da sala de aula e a suas consequências. Dar liberdade, orientar os alunos em uma aprendizagem que a conversa e interação façam partes da construção dos conhecimentos é um caminho inovador e criativo, porém, muitas vezes, é visto como problema por alguns educadores e não como um instrumento ao seu favor na elaboração das aulas.

Desde os tempos da sua formação básica, o professor já traz como modelo um aluno obediente, ou seja, um aluno apenas receptor. Quando inicia o exercício da profissão, mesmo tendo estudado teorias que dizem que a interação, o diálogo e liberdade em aula favorecem a aprendizagem, os seus costumes e determinação de manter a ordem sobressaem-se. Com isso, muitos agem de maneira rígida e controlada para manter domínio sobre a turma e também seguirem ideais e leis que o poder determina. 
Perrenoud (1999, p. 134) argumenta sobre a inquietude dos alunos, descrevendo o tempo e forma em que os sujeitos têm que ficar no ambiente escolar.

Sem dúvida, este é o imperativo primeiro quando se é condenado, vinte e cinco a trinta horas por semana, durante quarenta semanas por ano, a coexistir. No espaço exíguo da sala de aula, uma parte das conversações não tem outra razão de ser se não manifestar o pertencimento ao grupo, permitir a todos encontrar o seu lugar nele, ser reconhecido integralmente como seu membro, nele defender seus direitos, seus recursos, seu espaço vital. A aula é o principal quadro coletivo de vida das crianças e dos adolescentes, seis a sete horas por dia, durante anos. Portanto, é lá que eles se divertem, contam histórias, representam mil jogos relacionais da sua idade, fazem e desfazem bandos, criam e superam conflitos.

As conversações entre os alunos fazem parte das suas vidas, das suas relações, ou seja, são aprendizagens que eles já trazem da sua rotina diária, conhecimentos que podem ser utilizados para dar continuidade para as outras aprendizagens pertinentes à escola.

No momento em que o professor ocupa-se com outra atividade dentro da sala de aula, como atendimentos individuais, os alunos iniciam as famosas conversas paralelas, que só cessarão no momento que o educador der um basta, desencadeando, algumas vezes, em ameaças e penalizações.

É porque a comunicação é proibida que ela é divertida. Comunicar a despeito das proibições permite aos alunos manifestar uma certa solidariedade, é uma maneira de se defender contra a instituição (e contra o professor primário ou o secundário), de resistir à obrigação e à disciplina escolar, de desafiar a autoridade. E também, mais simplesmente, é um meio de matar o tempo e de suportar as longas horas de escola. (PERRENOUD, 1999, p. 136)

Para um professor dar uma aula construtiva, não basta somente ter na sua classe bons ouvintes, deve avaliar o que está sendo estudado, se tem sentido e se há compreensão por parte dos alunos. Uma das formas de perceber o entendimento das aulas é através do que o aluno expressa na sua fala com os colegas, com os professores e até nas relações dentro da escola. Arroyo (2000, p. 106) destaca que o papel do professor não é somente dar o conteúdo, 
"[...] para dar conta da formação dos educandos e não apenas de sua instrumentalização, é necessário um outro perfil de mestre que assuma que seu papel vai além de passar a matéria e avaliar se foi aprendida".

Freire (2006, p. 39) também reforça a ideia de que o professor deve ser um artista na sua função "[...] ensinar exige risco, aceitação do novo e rejeição a qualquer forma de discriminação". O educador pode deparar-se com situações inusitadas e complicadas dentro da sala de aula, a comunicação e o entendimento entre os participantes neste ambiente é fator fundamental para superar e modificar essas situações. O aluno silencioso, que não participa desses momentos de discussões e conflitos, pode ter o processo de aprendizagem comprometido. Por isso, o mestre, como agente da educação, deve relacionar sala de aula com o espaço social em que os educandos estão inseridos. Além disso, deve conhecer e entender a subjetividade de seus aprendizes, fazer ligações e interferir nos momentos propícios que eles precisarem.

Sendo assim, a sala de aula não pode ser um lugar de silêncio, a fala nesse ambiente é sinal que é um espaço democrático, com liberdade e condições de aprendizagem. Moraes (2003, p. 204) expressa com clareza como funciona o ambiente escolar que visa à produção de conhecimentos.

\footnotetext{
As salas de aulas são espaços para o desenvolvimento de experiências, para a manipulação nem sempre muito jeitosa dos materiais, um ambiente com ruídos, com movimentação das crianças, com uma certa liberdade para intervir e interferir sempre que o aluno julgar necessário. Nesses ambientes, não existe o silêncio nem o estado de contemplação dos ouvintes, que, na realidade, já não são ouvintes, mas construtores e autores de suas próprias obras.
}

Nessa perspectiva, diante dos autores estudados, a relação entre o silêncio dentro da sala de aula e as aprendizagens dos discentes necessita uma profunda reflexão por parte dos responsáveis pelo processo educativo. Essa questão deve ser avaliada, repensada, pois nem sempre o silêncio é benéfico e muito menos a conversa excessiva, tudo dependerá das atividades, das necessidades das aulas, as quais devem resultar num processo educativo que seja sempre favorável à formação de pessoas críticas e autônomas. 


\section{A trajetória da pesquisa}

O estudo foi realizado a partir de entrevistas a professores e alunos da rede pública e privada e, também, através de observações em uma turma de terceira série, com o intuito de saber como esses sujeitos veem o tema silêncio dentro da sala de aula.

A pesquisa é de cunho qualitativo, com análises através da coleta de dados com ênfase na pesquisa social, norteando questões que envolvem a forma que se constitui o silêncio para o professor e o aluno dentro da sala de aula. "A abordagem qualitativa aprofunda-se no mundo dos significados das ações e relações humanas, um lado não perceptível e não captável em equações, médias e estatísticas". (MINAYO, 1994, p. 22)

Como instrumentos de registro, os dados da entrevista e observações, possibilitaram o conhecimento de como o silêncio é visto e constituído dentro de uma sala de aula, diante do olhar das professoras e dos alunos entrevistados.

\section{Concepções dos professores sobre o silêncio}

O papel da escola é formar cidadãos aptos para viver em sociedade, ou seja, sujeitos que saibam se situar, que sejam críticos e autônomos no ambiente em que vivem. Esse ideal de educação remete à ideia de orientação, construção e elaboração do saber para um determinado fim, que seja do interesse e necessidade do aluno. Com este discurso, Freire (1993, p. 28) diz que o homem é o sujeito da sua educação, basta ele ter elementos para concretizá-la.

A educação é possível para o homem, porque este é inacabado e sente-se inacabado. Isso o leva a sua perfeição. A educação, portanto, implica uma busca realizada por um sujeito que é o homem. O homem deve ser o sujeito da sua própria educação. Não pode ser objeto dela. Por isso, ninguém educa ninguém.

A sala de aula deve proporcionar elementos para essa formação, deve ser um espaço de interação, liberdade de expressão e principalmente trocas entre professor, aluno e colegas.

Ao se traçar um paralelo entre conhecimento e silêncio, a pesquisa em foco trouxe respostas de professoras e alunos que estão em sala de aula, trazendo suas experiências e concepções sobre o assunto. Em cima das respostas, foram feitas reflexões, as quais não têm a intenção de explicitar, neste subitem, em que momentos 
o silêncio é oportuno e em que momentos ele não é, questão que será esclarecida até o final do artigo.

O primeiro questionamento em pauta tratava-se da seguinte pergunta: Como as professoras percebem o silêncio dos alunos na sala de aula?

Conforme as respostas das professoras, ele pode ser entendido de diferentes formas, dependendo do contexto. É necessário para a concentração no envolvimento das atividades, a escuta para compreender o que é dito em uma explicação ou até mesmo para ouvir uma história, ou seja, ele é importante em determinados momentos para se obter compreensão do que está sendo proposto. Também é relacionado como demonstração de interesse do que se está aprendendo. Esta relação significa que, o aluno mobilizado com algo que lhe interessa, fica calado.

No momento desse silêncio, o que ocorre são ligações com o que está sendo assimilado nas estruturas mentais, e com essas ligações que são feitas as conexões com o que está sendo proposto. Moraes (2003, p. 143) ressalta que

\footnotetext{
Os imprevistos e as mudanças provocam situações de desequilíbrio que exigem novas adaptações. E quando maior o desafio, maior a necessidade que organismo tem de assimilação, acomodação e auto-organização.
}

Também existe o silêncio estabelecido como regra na sala de aula. Uma das professoras se referiu ao silêncio imposto pelo professor como necessário, ela julga que a sua aula deve transcorrer dessa forma, pois a liberdade de interação dentro da sala de aula pode desfavorecer a ordem, o bom andamento das aprendizagens. Trata-se aqui de um silêncio imperativo.

Já outra professora refere-se ao silêncio dentro da sala de aula não como algo relevante e necessário em todos os momentos, pois deve haver comunicação entre os pares (contarem suas coisas, suas novidades, sua vida), a euforia por algo que os envolvam (alguma atividade interessante), pode ser troca de informações sobre alguma atividade solicitada, como um trabalho em grupo. Existem vários fatores que envolvem a conversa no ambiente escolar, situações que devem ser analisadas e dosadas dentro deste local, pois a fala é uma manifestação normal do ser humano em meio aos outros, ele é um ser social que como tal gosta de conversar interagir entre seus pares, Freire (1993, p. 28) diz que "O homem não é uma ilha. 
É comunicação. Logo, há uma estreita relação entre comunhão e busca". Observam-se assim leituras diferentes sobre esse tema, isso ocorre de acordo com o contexto e de professor para professor.

Seguindo o estudo, a segunda questão é se e essa comunicação entre os sujeitos na sala de aula pode favorecer uma melhor construção de aprendizagem entre eles?

Os professores dizem que é necessária a troca de experiências. Essa troca pode ocorrer numa fala/conversa e até mesmo no silêncio, pois se deve saber ouvir/observar. Ratificando, a fala/conversa e o silêncio têm seus momentos, todos eles são necessários para uma boa aula, há que se garantir a expressão livre entre os pares (alunos), como nas propostas de trabalho em que tenham que trocar informações, compartilhar conhecimentos e negociar estratégias.

Pensar na pós-moderninade, na desconstrução das verdades absolutas e no mundo que está em constante movimento são fatores muito relevantes na educação atual. Está sendo constantemente discutido pensado e repensado por pessoas que estudam as relações, mudanças e formas adequadas de lidar e preparar os sujeitos para esta realidade imposta nos dias de hoje. Garcia (1988, p. 29) relaciona a pós-modernidade na educação da seguinte forma:

Acreditamos que a educação pós-moderna seja uma educação de transição. Está num mundo no qual, por um lado, a técnica se sobrepõe ao homem, dividindo-o entre a vida confortável e o medo de uma técnica arrasadora; por outro, revive a aspiração ou a nostalgia de uma vida na qual seja possível a alegria no desfraldar da própria personalidade e na relação do homem com o seu mundo cotidiano. Está pedindo uma nova educação.

Compreende-se, então, que hoje em dia não se quer um aluno mudo/silencioso por causa do medo de falar, mas um aluno que expresse seus pensamentos, que conte suas histórias, que relacione os temas discutidos em sala de aula com suas vivências. Em várias situações, o que interessa aos alunos não é o que é proposto pelo professor, por isso cabe ao docente aproveitar e refletir sobre o que realmente a criança quer e necessita aprender, enfim, valorizar uma conversa paralela (é aqui que muitas vezes se escuta: cala a boca, Joãozinho!) pode ser o início de uma longa conversa. No controle pelo silêncio, no fica quieto, Joãozinho, exclui-se totalmente a possibilidade de conhecer/identificar o interesse do aluno. 
São nessas relações de conversa no ambiente escolar, que há alunos que se sobressaem aos demais, pois monopolizam o diálogo dentro da sala de aula, intimidando os mais introvertidos. Aqui se tem um silêncio não por não saber se expressar, mas por não existir a vez do outro. Uma das professoras entrevistadas fez o seguinte comentário:

Alunos mais extrovertidos necessitam falar. São alunos que querem marcar sua presença (incomodando, chamando atenção, por contestação etc.). Os quietos nem sempre sabemos porque são quietos.

Por não saber como lidar com um aluno desse perfil (falador), o professor acaba dando mais atenção a ele, esquecendo aquele silencioso que talvez tenha muito a contribuir. Ainda, segundo a professora, se há professores que não sabem o que fazer com os ditos falantes que querem marcar sua presença, há docentes que aproximam e relacionam as falas desse aluno com os temas em estudo, fazendo com que até o silencioso participe. Ou seja, uma conversa inicialmente atrapalhadora e solta torna-se alvo de estudo. E, termina falando que: "Não basta ser professor, tem que ser um malabarista, um artista dentro da sala de aula para despertar o interesse do aluno".

Para outra entrevistada, há alunos falantes, mas integradores, sua fala é construtiva e pode fornecer mais subsídios para o andamento da atividade. Nesse contexto, esse sujeito é considerado extrovertido, participativo e crítico, é visto como um ponto a favor nas aulas, pois favorece a interação entre os colegas nos debates, construindo assim aprendizagens numa visão coletiva e integradora. Freire (1993, p. 29) relaciona o ato de educar com amor, atenção e doação.

\footnotetext{
Não há educação sem amor. O amor implica luta contra o egoísmo. Quem não é capaz de amar os seres inacabados não pode educar. Não há educação imposta, como não há amor imposto. Quem não ama não compreende o próximo, não o respeita.
}

A criança já chega com bagagem de vida, ela não é uma tábula rasa. O que já foi aprendido no decorrer da sua existência não será apagado na vida escolar, será agregado aos saberes novos, alguns serão modificados e outros serão reforçados diante das 
suas concepções e necessidades. Freire (1993, p. 32) fala que "[...] a educação deve ser desinibidora e não restritiva. É necessário darmos oportunidade para que os educandos sejam eles mesmos."

Impor regras e limites é necessário na visão das professoras. Para um bom andamento no processo educativo, há necessidade de analisar vários fatores na turma que se está ministrando as aulas, como, por exemplo, a faixa etária, localidade e contexto em que vivem, ou seja, o professor quando determina regras tem que estar aberto para conhecer as crianças e trocar ideias de organização no espaço escolar.

Segundo as entrevistadas, quando há desorganização e muita conversa paralela, a dificuldade de manter a ordem se instaura no ambiente escolar e assim se faz necessário usar métodos de punição, a exemplo da nota. A nota é um artefato que o educador tem ao se alcance e pode ser usada para punir aqueles que estão fora do ideal escolar, tentando estabelecer com esse método a organização e um bom andamento da aula.

Sobre a importância de impor regras, ordem e punições na sala de aula. Uma das professoras relata, sem descartar a organização no ambiente, que o educador deve dosar os deveres dos alunos, de forma que os sujeitos tenham prazer de aprender. "É necessário tirar o sentido de obrigatoriedade da palavra educação, ela deve ser vista como algo que ajudará na constituição do individuo, favorecendo os seus desejos e anseios".

Ela ainda diz que:

[...] estabelecer momentos com atividades que proporcionem o diálogo entre os alunos, pode parecer, muitas vezes, para quem está de fora, que estão bagunçando, quando na verdade estão trabalhando produtivamente. Não é obrigatoriamente o recinto estar em profundo silêncio para estar sendo produzido conhecimento.

Silêncio e conversa são dois elementos importantes da sala de aula que podem ser benéficos ou não, pois depende do contexto, da situação, segundo o relato das professoras. Para elas, o que deve ser considerado é a ideia equivocada de que o silêncio absoluto em sala de aula garante uma melhor aprendizagem e de que só o professor pode ter o direito da palavra. Assim como também considerar que a conversa solta e desvinculada do trabalho proposto pelo educador também reverta à aprendizagem.

Há de se garantir espaço para o silêncio e conversa em sala de aula, conversa entendida como elemento importante na construção 
de conhecimento e forma de expressão e silêncio como concentração e respeito ao colega que está aprendendo. Freire (2006, p. 103) diz que "[...] o clima de respeito que nasce nas relações justas, sérias, humildes, generosas, em que a autoridade docente e as liberdades dos alunos se assumem eticamente, autentica o caráter formador do espaço pedagógico." O professor deve assumir, em caráter de respeito ao aluno, atitudes dentro da sala de aula que possibilite a liberdade, autonomia e compreensão, com o intuito de chegar ao ponto principal da educação, que é o saber.

\section{Como é visto o silêncio pelos alunos}

O silêncio na sala de aula é percebido pelos alunos entrevistados como fator de importância nos momentos das explicações do professor e de atividades que exijam atenção e concentração. Eles relatam que precisam ouvir para assimilar o que vão aprender. A respeito desse silêncio, Freire (2006, p. 132) ressalta que:

\footnotetext{
A importância do silêncio no espaço da comunicação é fundamental. De um lado, me proporciona que, ao escutar, como sujeito e não como objeto, a fala comunicante de alguém, procure entrar no movimento interno do seu pensamento, virando linguagem, de outro, torna possível a quem fala realmente comprometido com comunicar e não com fazer puros comunicados escutar a indagação a dúvida, a criação de quem escutou.
}

Alguns alunos relataram que nos momentos que um colega está conversando, desviando o sentido da aula atrapalha e desfavorece o entendimento do conteúdo, pois o professor necessita fazer pausas nas explicações para chamar a atenção dos alunos que estão atrapalhando o desenvolvimento das atividades. Há uma necessidade, diante das respostas dos entrevistados, de ter silêncio na sala de aula, pois, segundo eles, existem momentos de interação, relatam que é produtivo falar e debater o assunto estudado nos momentos adequados a essa proposta.

Um aluno relatou que prefere ficar somente escutando, pois sente timidez em falar em público, apesar de ser dentro da sala de aula com seus colegas e professor, teme ser rechaçado e ridicularizado pelo que disser. É natural algumas crianças se portarem dessa forma, pode ser pela educação dentro do espaço familiar, 
pelo sistema dentro da escola ou também pela sua constituição individual, sua personalidade. São vários os fatores que envolvem essa questão, que pode favorecer ou desfavorecer a relação do conhecimento construído na escola. Perrenoud (2000, p. 151) mencionando as concepções de outro autor, fala das dificuldades em relação a personalidades dos alunos:

Toda abordagem psicanalítica, didática ou psicológica da classe sugere que os agentes, inclusive os adultos, não sabem exatamente o que fazem. O vinculo educativo (Cifali, 1994) é muito complexo, pois mobiliza demasiadas camadas de sua personalidade para que o professor domine racionalmente $o$ todo da relação que constrói com seus alunos.

A relevância sobre a individualidade de cada aluno aponta como peça fundamental para um desenvolvimento satisfatório dos trabalhos propostos. A caracterização de cada componente na sala de aula e a formação de grupos de estudo favorecem a aproximação entre os alunos, promovendo a troca e a aceitação do novo, compartilhando o que já sabe com as novas descobertas. Moraes (2003, p. 224) ressalta que:

O aprendizado autônomo pressupõe flexibilidade, plasticidade, facilidade para mudar valores, para promover diálogos e potencializar habilidades de comunicação no que se refere à cooperação, à coordenação e à decisão decorrentes das vivências de trabalho em grupo na procura de soluções conjuntas para os problemas; esse aprendizado reconhece a importância das experiências individuais e coletivas, além de reconhecer a participação de cada membro do grupo na construção do saber, que já não é individual e, sim, coletivo.

Os trabalhos em grupo proporcionam a integração e comunicação entre os sujeitos, podendo, dessa forma, quebrar algumas barreiras que se originam na timidez de expor pensamentos e ideias. Quando questionados a respeito desses trabalhos, os alunos responderam que gostam de trabalhar em grupo, porque trocam ideias, pensam juntos. Na visão deles, a aprendizagem ocorre de maneira mais livre e solta porque podem conversar sem restrição e controle. No relato de um dos entrevistados, fez a seguinte referência a esse assunto: 
Trabalhar em grupo é muito bom, pois temos que fazer o que a professora nos determinou. Para dar conta e fazer um bom trabalho, nos empenhamos tanto que até esquecemos das outras coisas, acabamos falando e trocando ideias somente sobre o que estamos estudando.

Apesar, de algumas vezes, um aluno ou outro ficar arredio nos momentos de trabalhar em grupo, seja por timidez, egoísmo, seja por aversão a algum colega, esse tipo de atividade proporciona o desenvolvimento da criatividade, do senso crítico, da solidariedade e a condição de sentir que necessita da ajuda do outro, necessita compartilhar para constituir-se como um ser humano atuante na sociedade.

\section{A representação do silêncio dentro da sala de aula}

A partir das observações das aulas em uma terceira série, percebeu-se que a relação entre o silêncio e a construção de aprendizagem dentro do ambiente escolar, com a visão voltada à prática educativa, tem prioridade nos momentos de ouvir o professor nas explicações, orientações e quando há necessidade de concentração na atividade proposta.

O silêncio é instaurado em momentos específicos, priorizando a orientação e concentração, que são elementos indispensáveis para o aluno construir e fortalecer o seu conhecimento individual. Como existe a necessidade do aluno comunicar-se, também existe a importância do silêncio para refletir, pensar e assimilar o conhecimento. O saber ouvir reflete no saber falar, respeitar a opinião do outro, construindo a sua opinião de acordo com a trajetória de comunicabilidade entre as experiências vividas tanto na escola como fora dela.

Há crianças que se dispersam em conversas paralelas, ao comando da professora, voltam à atenção ao que está sendo apresentado na aula. Existe a dificuldade da concentração por alguns alunos, principalmente na segunda feira, quando eles voltam cheios de novidades do final de semana. Os meninos falam sobre o futebol, videogame e as meninas sobre passeios, compras e roupas.

A aula começa com esse burburinho, a professora deixa-os falarem, extravasarem para após dar início à aula. É uma tática usada pela educadora que favorece a relação de respeito entre 
eles. Fazer acordos, promover condições de trabalho é um ponto positivo para um bom entendimento professor, aluno e colegas.

No momento que o professor instaura direitos e deveres coletivos dentro do ambiente escolar, a responsabilidade deixa de ser única e exclusivamente dele. Os alunos, automaticamente, começam a se sentirem pequenos adultos, responsáveis pelo bom andamento da aula. E, quando um colega, por algum momento, não faz o que foi combinado, os mesmos tratam de chamar a sua atenção e fazer o sujeito voltar a atender o que foi estipulado pela classe. Com essa postura, o professor deixa de ser a autoridade dentro da escola e passa a ser visto como um parceiro, uma pessoa que está lá para ajudar e não só para controlar e punir.

Nos trabalhos em grupo, o desenvolvimento é criativo e produtivo. As crianças visivelmente gostam mais desse tipo de atividade pelo fato delas estarem livres para conversarem, caminharem, interagir com os colegas e professor. A troca de ideias nas conversas, no instante que se está construindo o trabalho, demonstra que trabalhar em grupo favorece a cooperação, a imaginação, o envolvimento e principalmente o prazer de aprender de vivenciar o andamento da proposta de estudo.

A relação entre colegas, nesses momentos, tem o lado prejudicial, quando há os grupos formados, alguns alunos sentem-se excluídos, colocados de lado pelos colegas. Isso é bem trabalhado pela professora, pois ela determina a construção dos grupos de uma forma que não prejudique ninguém. É discutido com todos e, quando não há acordo, ela faz um sorteio, algumas crianças se revoltam por não ficar com seus colegas preferidos, mas, depois de alguma resistência, a determinação de construir o trabalho prevalece e todos começam a conversar e discutir como pretendem produzir o que foi determinado.

Essa comunicação faz com que os sujeitos vejam que é muito importante a união e a parceria, sejam nos momentos de estudo, seja em qualquer outra oportunidade. Além disso, a interação e o respeito aos instantes, que se fazem necessário o ouvir e o falar, são fatores de suma importância para uma boa produção e andamento no processo educativo. 


\title{
Considerações finais
}

Diante das respostas obtidas, através das entrevistas e observações, constatou-se que o silêncio, quando está presente em forma de concentração nos momentos de ouvir e produzir individualmente as atividades, tem um propósito construtivo e positivo. Ele é importante para que o sujeito possa refletir e assimilar o que está aprendendo, fazer as suas descobertas e relacioná-las ao que já conhece. Por esses fatores, o silêncio é um elemento imprescindível em determinados momentos das aulas.

Ele é necessário e indispensável, porém, em excesso, pode representar algum problema, pois a comunicação é peça principal na construção de aprendizagens. Todos os entrevistados (professoras e alunos) foram enfáticos ao dizerem que o diálogo dentro do ambiente escolar proporciona a troca de ideias e amplia as possibilidades de aquisição do saber.

Com as análises feitas do estudo proposto sobre o tema silêncio, conclui-se que ele constrói aprendizagens em momentos necessários e específicos, fora desse contexto é considerado prejudicial à construção de conhecimentos da criança, pois os humanos são seres comunicativos e como tal necessitam de integração para viver em harmonia dentro do ambiente social ao qual estão inseridos.

\section{Silence in the classroom}

\begin{abstract}
This article has as aim at doing a study about these following questions: how silence is built inside the school environment and in what moments it disturbs or helps in the students learning. This research in based on qualitative aspects and it was developed in a public elementary school of Osório city of north coastline in Rio Grande do Sul. The collection of data was done through interviews with the first grades teachers and students and observations in the classroom to verify their opinions and beliefs that they have about silence as the responsible for building of knowledge inside the school environment.
\end{abstract}

Key words: Silence Pedagogy. Learning. School environment.

\section{Referências}

ARROYO, Miguel González. O subsolo comum de nossa docência.

In:__ Oficio de mestre: imagens e auto-imagens. Petrópolis, RJ: Vozes, 2000 .

FOUCAULT, Michel. Vigiar e punir: nascimento da prisão. Petrópolis, RJ: Vozes, 2004.

FREIRE, Paulo. Educação e mudança. Tradução de Moacir Gadotti e Lílian Lopes Martin. 8 ed. Rio de Janeiro: Paz e Terra, 1993. 
FREIRE, Paulo. Pedagogia da autonomia: saberes necessários para a prática educativa. São Paulo: Paz e Terra, 2006.

GARCÍA HOZ, Victor. Pedagogia visível: educação invisível. Tradução de Claudia Aimée Schilling. São Paulo: Nerman, 1988.

GIMENO SACRISTÀN, José. Educar e conviver na cultura global: exigências da cidadania. Porto Alegre: Artmed, 2002.

MINAYO, Maria Cecília de Souza et al. Pesquisa social: teoria, método e criatividade. Petrópolis, RJ: Vozes, 1994.

MORAES, Maria Cândida. O paradigma educacional emergente. São Pau1o: Papirus, 2003.

PERRENOUD, Philippe. Avaliação da excelência à regulação das aprendizagens: entre duas lógicas. Porto Alegre: Artes Médica, 1999.

. Dez novas competências para ensinar: convite à viagem. Porto Alegre: Artes Médicas, 2000.

Artigo submetido em 25/05/2012 e aceito para publicação em 12/06/2012. 